\title{
Ultrasonographic Diaphragmatic Motion Analysis and Its Correlation With Pulmonary Function in Hemiplegic Stroke Patients
}

\author{
Kang-Jae Jung, MD, Ji-Young Park, MD, Do-Won Hwang, MD, \\ Jeong-Hawn Kim, MD, Jae-Hyung Kim, MD, PhD
}

Department of Rehabilitation Medicine, Eulji University Hospital, Eulji University School of Medicine, Daejeon, Korea

Objective To evaluate diaphragmatic motion via M-mode ultrasonography and to correlate it with pulmonary function in stroke patients.

Methods This was a preliminary study comprised of ten stroke patients and sixteen healthy volunteers. The M-mode ultrasonographic probe was positioned in the subcostal anterior region of the abdomen for transverse scanning of the diaphragm during quiet breathing, voluntary sniffing, and deep breathing. We analyzed diaphragmatic motion and the relationship between diaphragmatic motion and pulmonary function.

Results All stroke patients had restrictive pulmonary dysfunction. Compared to that exhibited by control subjects, stroke patients exhibited a significant unilateral reduction in motion on the hemiplegic side, primarily during volitional breathing. Diaphragmatic excursion in right-hemiplegic patients was reduced on both sides compared to that in control subjects. However, diaphragmatic excursion was reduced only on the left side and increased on the right side in left-hemiplegic patients compared to that in control subjects. Left diaphragmatic motion during deep breathing correlated positively with forced vital capacity ( $\mathrm{rho}=0.86, \mathrm{p}=0.007)$ and forced expiratory volume in 1 second ( $r h o=0.79, \mathrm{p}=0.021$ ).

Conclusion Reductions in diaphragmatic motion and pulmonary function can occur in stroke patients. Thus, this should be assessed prior to the initiation of rehabilitation therapy, and M-mode ultrasonography can be used for this purpose. It is a non-invasive method providing quantitative information that is correlated with pulmonary function.

Keywords Stroke, Hemiplegia, Diaphragm, Ultrasonography, Pulmonary function tests

Received July 16, 2013; Accepted September 24, 2013

Corresponding author: Ji-Young Park

Department of Rehabilitation Medicine, Eulji University Hospital, Eulji University School of Medicine, 95 Dunsanseo-ro, Seo-gu, Daejeon 302799, Korea

Tel: +82-42-611-3631, Fax: +82-42-611-3633, E-mail: danielpjy@naver.com

@ This is an open-access article distributed under the terms of the Creative Commons Attribution Non-Commercial License (http://creativecommons. org/licenses/by-nc/3.0) which permits unrestricted noncommercial use, distribution, and reproduction in any medium, provided the original work is properly cited.

Copyright $\odot 2014$ by Korean Academy of Rehabilitation Medicine

\section{INTRODUCTION}

The diaphragm is the major respiratory muscle, contributing up to $70 \%$ to resting lung ventilation. Since the diaphragm has a major role in respiration, knowledge of the effects of stroke on diaphragmatic function is important for the rehabilitation of hemiplegic patients. Control of the diaphragm occurs via two major descending pathways: the corticospinal pathway from the cortex 
to the respiratory motor neurons, which is responsible for voluntary breathing; and the bulbospinal pathway, which descends from the medulla through the ventrolateral quadrant of the spinal cord to the respiratory motor neurons and controls automatic breathing. There is also a putative connection between the motor cortex and the pontomedullary respiratory centers [1-3]. Because of the complexity of diaphragmatic motor control, the effect of stroke on diaphragmatic motion is controversial. Houston et al. [4] suggested that a significant bilateral reduction in diaphragmatic motion occurs during deep breathing. However, Cohen et al. [5] proposed a significant decrease in diaphragmatic excursion on the hemiplegic side during volitional breathing compared to that of automatic breathing.

Diaphragmatic motion can be readily studied with fluoroscopy. However, fluoroscopy is not portable and requires ionizing radiation. An alternative method is ultrasonography. Ultrasonography not only avoids these disadvantages of fluoroscopy but, unlike conventional fluoroscopy, can also simultaneously determine direct quantitative and qualitative information $[6,7]$. Recent studies have reported that M-mode ultrasonography is reproducible, reliable, and relatively easy to use for analyzing diaphragmatic motion $[8,9]$. We found no published study that used M-mode ultrasonography to separately compare diaphragmatic motion for the right and left sides during the three types of breathing (quiet breathing, voluntary sniffing, and deep breathing) in stroke patients within 4 weeks after onset. Thus, in the present study, we sought to determine the effects of stroke on diaphragmatic motion using M-mode ultrasonography and to correlate diaphragmatic motion with pulmonary function in hemiplegic stroke patients.

\section{MATERIALS AND METHODS}

\section{Subjects}

Ten stroke patients (eight men and two women; mean age, $59.7 \pm 12.9$ years) who were within 4 weeks after onset were recruited. Four patients had right-sided hemiplegia, and six had left-sided hemiplegia. Only patients with a first monohemispheric stroke above the brain stem, as documented via computed tomography or magnetic resonance imaging, were included. Exclusion criteria included a history of smoking, significant cardiorespi- ratory or other neuromuscular disease, tracheostomy, obesity (body mass index $\geq 30 \mathrm{~kg} / \mathrm{m}^{2}$ ), chest deformity, cognitive impairment (Mini-Mental State Examination score $\leq 20$ points), severe aphasia, or anosognosia rendering patients uncooperative. Selection of control subjects (six men and ten women; mean age, 56.1 \pm 9.3 years) was based on the same exclusion criteria.

All patients and healthy subjects were informed of the study and provided written, informed consent.

Pulmonary function test, blood gas monitoring, and functional level measurements

Pulmonary function testing was performed, including measurement of forced vital capacity (FVC), forced expiratory volume of 1 second $\left(\mathrm{FEV}_{1}\right)$, and $\mathrm{FEV}_{1} / \mathrm{FVC}$ ratio using an MS03 spirometer (Micro Medical Ltd., Chatham Maritime, Kent, UK). The tests were performed with the subject in a sitting position. All values were compared to normal reference ranges and interpreted according to the results of previous studies [10]. Capnography and pulse oximetry were performed with a CO2SMO monitor (Novametrix Medical Systems Inc., Wallingford, CT, USA) for non-invasive blood gas measurement. Sensory probes of the pulse oximeter of the CO2SMO device were attached to the affected index finger to reduce movement artifacts during monitoring of oxygen saturation [11]. A nasal carbon dioxide $\left(\mathrm{CO}_{2}\right)$ sampling cannula (Cat. No. 8781) connected to dehumidification tubing was used for end-tidal $\mathrm{CO}_{2}$ monitoring. These values were measured every other day, and mean values were used for analysis.

The Korean Modified Barthel Index (K-MBI) was used to evaluate the subject's ability to perform daily living activities.

\section{Ultrasonographic measurement}

A Philips iU22 (Philips Medical System, Bothell, WA, USA) ultrasonographic machine was used, programmed for a depth of $250 \mathrm{~mm}$ with the slowest sweep speed (10 seconds per screen) and equipped with a 1-5 MHz convex transducer for M-mode analysis. All subjects remained in the supine position, with a $30^{\circ}$ incline of the upper part of the body. Before each examination, all subjects were asked to rest for at least 30 minutes. Because diaphragmatic excursion between the right and left hemidiaphragms varies, even in normal subjects [12,13], we measured diaphragmatic motion on each side inde- 
pendently.

\section{Ultrasonographic study of the right hemidiaphragm}

Ultrasonographic analysis of diaphragmatic excursion was performed as described in previous studies [8,9]. An anterior subcostal approach was used for visualizing the right diaphragm (Fig. 1). This required the transducer to be placed on the abdomen at the right mid-clavicular line in the anterior subcostal region. Initially, the inferior vena cava was identified in the right of the field using Bmode scanning; the gall bladder then was found in the middle of the screen. The right hemidiaphragm appeared as a thick, curved line with hyperechogenicity. The transducer was directed medially, cranially, and dorsally so that the ultrasonographic beam reached the posterior third of the right diaphragm. The greatest craniocaudal excursion occurs in this region of the diaphragm $[14,15]$. In this position, imaging was then changed to M-mode to measure diaphragmatic motion by placing the Mbeam line at approximately $30^{\circ}$ from the craniocaudal central line. The hemidiaphragm was measured during quiet breathing, voluntary sniffing [16], and deep breathing.

\section{Ultrasonographic study of the left hemidiaphragm}

A subcostal approach was used, with the probe positioned between the anterior and mid-axillary lines (Fig. 2). B-mode transverse scanning was performed to visualize the maximum distance of the hilum from the spleen at the center of the screen. M-mode ultrasonography could then assess the diaphragmatic motion pattern,
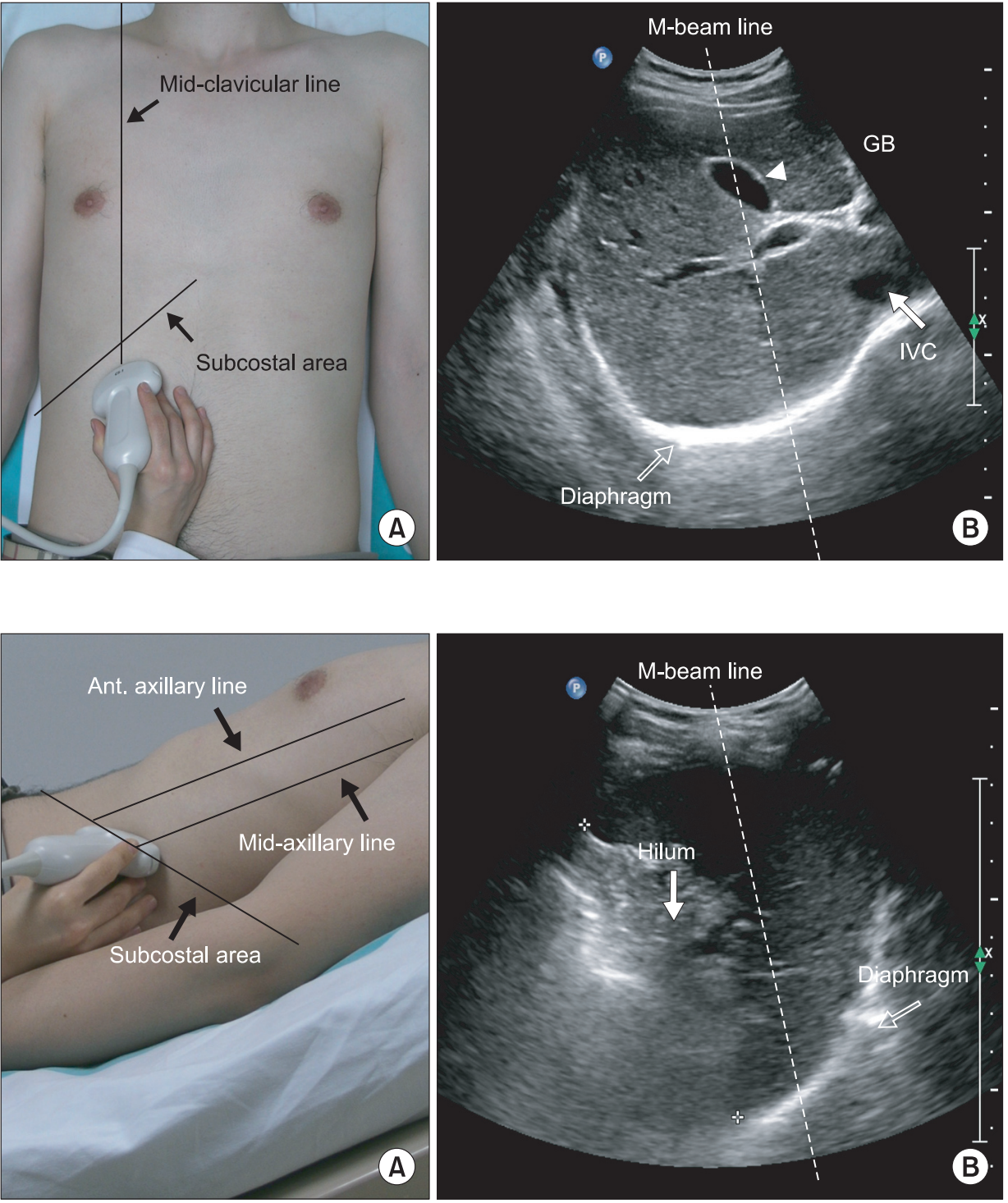

Fig. 1. (A) Ultrasonographic approach to the right diaphragm. The transducer was placed on the anterior subcostal region at the right mid-clavicular line. (B) Right diaphragm viewed as a hyperechogenic line on the B-mode screen. The inferior vena cava (IVC) is visible on the right side of the screen, and the gall bladder is present at the center of the screen. The Mbeam line is angled approximately $30^{\circ}$ to the vertical line.

Fig. 2. (A) Ultrasonographic approach to the left diaphragm. The transducer was placed on the anterior subcostal region between the anterior and midaxillary lines. (B) Left diaphragm viewed as a hyperechogenic line on the $\mathrm{B}$-mode screen. The hilum of the spleen is viewed at the maximum distance on the screen. The M-beam line is angled approximately $30^{\circ}$ to the vertical line. 
placing the M-beam line as described above during the three types of breathing.

\section{Measured variables}

Diaphragmatic excursion was measured with the Mmode setting. Measurement of the amplitude of the excursion during quiet breathing and deep breathing measurements was performed by drawing a vertical line with the first caliper placed at the foot of the inspiration slope corresponding to the end of normal expiration with the other caliper fixed at the inspiratory peak (Fig. 3A, B). For the amplitude of excursion during voluntary sniffing, the vertical axis of the tracing from the baseline to the point of the apex of the inspiration graph was measured (Fig. 3C). Five consecutive respiratory cycles were recorded for each type of breathing, and maximal values were selected.

\section{Statistical analysis}

A comparative analysis was conducted between the control subjects and the hemiplegic patients using the Mann-Whitney U test with respect to anthropometric data, blood gas monitoring, and pulmonary function. A Kruskal-Wallis test was used to determine significant differences among the three groups (healthy subjects and right- and left-hemiplegic patients) in the mean values of diaphragmatic excursion; a Mann-Whitney U test with a Bonferroni correction was used for post-hoc testing. Finally, Spearman correlation analysis was used to de- termine the association between diaphragmatic excursion and pulmonary function or K-MBI scores in stroke patients. It was also used to determine the correlation between pulmonary function and K-MBI scores in stroke patients. Data are expressed as the mean \pm standard deviation. p-values $<0.05$ were considered to indicate statistical significance. All statistical tests were conducted using the SPSS software ver. 12.0 (SPSS Inc., Chicago, IL, USA).

\section{RESULTS}

We found no statistically significant difference between healthy subjects and stroke patients in age, height, weight, or body mass index (Table 1). No significant difference between healthy subjects and stroke patients was observed in blood oxygen saturation $\left(\mathrm{SaO}_{2} ; \mathrm{p}=0.116\right)$ or end-tidal carbon dioxide $\left(\mathrm{ETCO}_{2} ; \mathrm{p}=0.424\right)$. There was a tendency for the mean $\mathrm{SaO}_{2}$ and mean $\mathrm{ETCO}_{2}$ values to be lower in stroke patients than in control subjects. All control subjects had normal values on pulmonary function testing. However, stroke patients exhibited differing degrees of ventilatory restrictive dysfunction, ranging from mild (five cases) to moderate (four cases) to severe (one case). As a result, significant differences in the mean values of $\mathrm{FEV}_{1}\left(\mathrm{~L} ; \mathrm{p}=0.022\right.$ ), $\mathrm{FEV}_{1}$ (\% of predicted; $\mathrm{p}<0.001$ ), FVC ( $\mathrm{L} ; \mathrm{p}=0.008)$, and FVC (\% of predicted; $\mathrm{p}<0.001)$ were observed between stroke patients and control subjects.

Among healthy subjects, men had greater diaphrag-
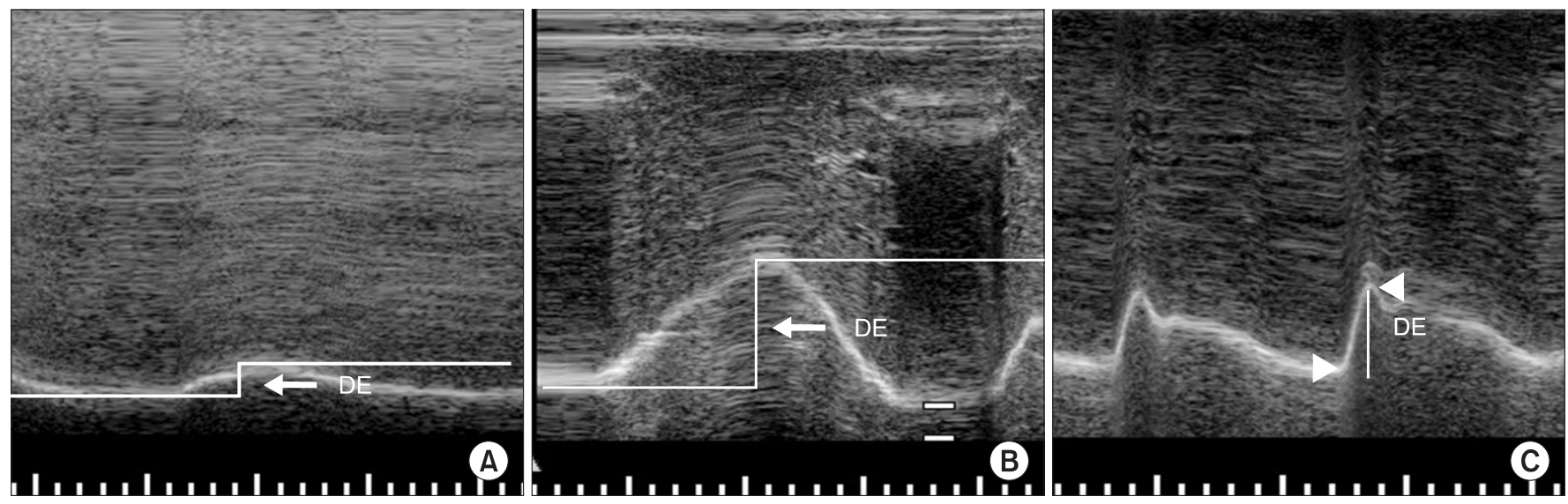

Fig. 3. (A) Measurement of diaphragmatic excursion (DE) during quiet breathing on the M-mode screen. (B) Measurement of DE during deep breathing on the M-mode screen. DE is represented by the vertical axis between the line passing through the end of the normal expiration and inspiratory peaks. (C) Measurement of DE during voluntary sniffing on the M-mode screen. DE is represented by the vertical line between the baseline and the peak of the inspiration graph. 
matic motion than did women, except on the right side during quiet breathing and voluntary sniffing (Table 2). Compared to control subjects, left-hemiplegic patients exhibited a significant unilateral reduction in diaphragmatic excursion on the hemiplegic side during quiet breathing, voluntary sniffing, and deep breathing, and right hemiplegic patients did so during deep breathing (Fig. 4 and Tables 3, 4). We found no significant difference in diaphragmatic excursion between right-hemiplegic patients and control subjects during quiet breathing or

Table 1. Anthropometric data and pulmonary function test results

\begin{tabular}{|ccc}
\hline & Controls & Stroke patients \\
\hline Age $(\mathrm{yr})$ & $56.13 \pm 9.31$ & $59.70 \pm 12.90$ \\
\hline Height $(\mathrm{cm})$ & $160.00 \pm 8.25$ & $164.00 \pm 9.70$ \\
Weight $(\mathrm{kg})$ & $61.19 \pm 9.94$ & $62.10 \pm 12.96$ \\
$\mathrm{BMI}$ & $24.01 \pm 2.67$ & $23.09 \pm 4.94$ \\
$\mathrm{SaO}_{2}(\%)$ & $97.44 \pm 1.79$ & $96.20 \pm 2.39$ \\
$\mathrm{ETCO}_{2}(\mathrm{mmHg})$ & $34.88 \pm 2.13$ & $34.10 \pm 2.88$ \\
\hline $\mathrm{FEV}_{1}(\mathrm{~L})$ & $2.29 \pm 0.48$ & $1.83 \pm 0.52^{*}$ \\
\hline $\mathrm{FEV}_{1}(\%$ of predicted) & $92.44 \pm 10.24$ & $66.00 \pm 8.87^{* *}$ \\
\hline $\mathrm{FVC}(\mathrm{L})$ & $2.64 \pm 0.52$ & $2.02 \pm 0.55^{* *}$ \\
\hline $\mathrm{FVC}(\%$ of predicted) & $88.25 \pm 7.88$ & $58.60 \pm 9.37^{* *}$ \\
\hline $\mathrm{FEV}_{1} / \mathrm{FVC}(\%)$ & $86.68 \pm 4.62$ & $91.24 \pm 6.61$ \\
\hline
\end{tabular}

Values are presented as mean \pm standard deviation.

$\mathrm{BMI}$, body mass index; $\mathrm{SaO}_{2}$, blood oxygen saturation; $\mathrm{ETCO}_{2}$, end-tidal carbon dioxide; $\mathrm{FEV}_{1}$, forced expiratory volume in 1 second; FVC, forced vital capacity; $\mathrm{FEV}_{1}$ / $\mathrm{FVC}$, ratio of $\mathrm{FEV}_{1}$ to FVC.

${ }^{*} \mathrm{p}<0.05,{ }^{* *} \mathrm{p}<0.01$.

(A)

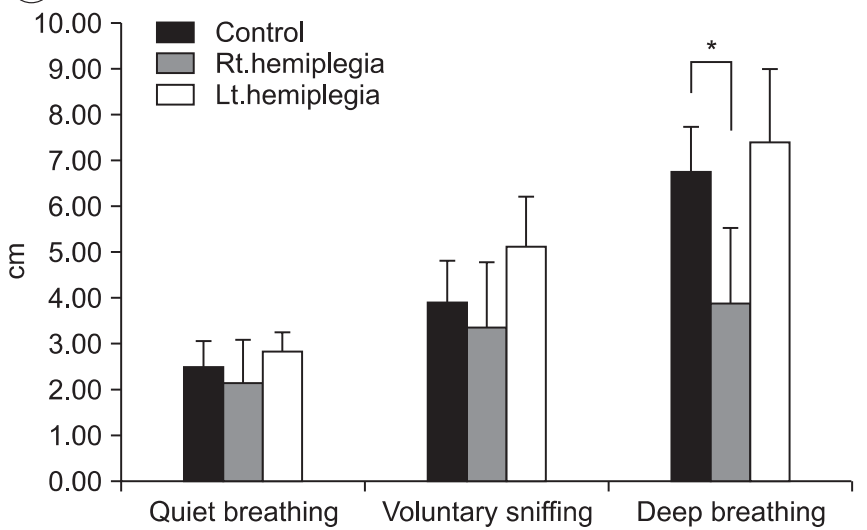

voluntary sniffing. However, there was a tendency for the diaphragmatic motion to be reduced in right-hemiplegic patients relative to control subjects. Diaphragmatic excursion in right-hemiplegic patients was reduced on both sides compared to control subjects. However, diaphragmatic excursion in left-hemiplegic patients was reduced only on the left hemiplegic side, and it was increased on the right, nonhemiplegic side, compared to control subjects.

We observed a significant positive correlation between left diaphragmatic excursion during deep breathing and $\mathrm{FEV}_{1}(\mathrm{rho}=0.7, \mathrm{p}=0.021)$ and FVC (rho=0.86, $\left.\mathrm{p}=0.007\right)$ in stroke patients. However, no significant correlation between diaphragmatic excursion and K-MBI scores was observed. K-MBI scores were also not significantly correlated with pulmonary function in hemiplegic patients.

Table 2. Diaphragmatic excursion in healthy subjects

\begin{tabular}{lccc}
\hline & $\begin{array}{c}\text { Quiet } \\
\text { breathing }\end{array}$ & $\begin{array}{c}\text { Voluntary } \\
\text { sniffing }\end{array}$ & $\begin{array}{c}\text { Deep } \\
\text { breathing }\end{array}$ \\
\hline Right diaphragm (cm) & & & \\
Men & $2.30 \pm 0.43$ & $3.64 \pm 0.98$ & $7.16 \pm 0.95$ \\
Women & $2.67 \pm 0.59$ & $4.11 \pm 0.84$ & $6.50 \pm 0.91$ \\
Left diaphragm (cm) & & & \\
$\quad$ Men & $2.43 \pm 0.51$ & $3.89 \pm 0.14$ & $7.16 \pm 0.56$ \\
Women & $2.37 \pm 0.66$ & $3.71 \pm 0.65$ & $5.78 \pm 0.76$ \\
\hline
\end{tabular}

Values are presented as mean \pm standard deviation.

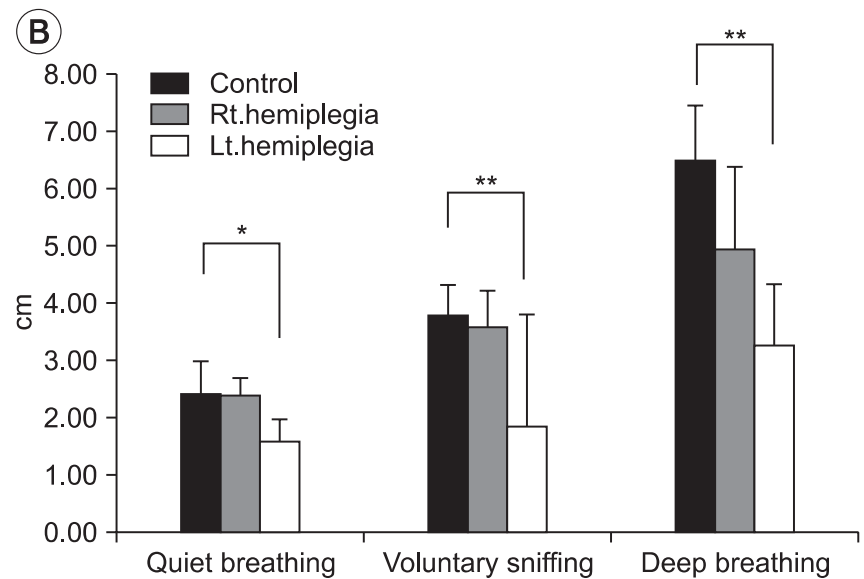

Fig. 4. (A) Right diaphragmatic excursion in control subjects and right- and left-hemiplegic stroke patients. (B) Left diaphragmatic excursion in control subjects and right- and left-hemiplegic stroke patients. ${ }^{*} \mathrm{p}<0.05,{ }^{* *} \mathrm{p}<0.01$. 
Kang-Jae Jung, et al.

Table 3. Right diaphragmatic excursion in control subjects and right- and left-hemiplegic patients (unit, $\mathrm{cm}$ )

\begin{tabular}{lccc}
\hline & Control subjects & Right-hemiplegic patients & Left-hemiplegic patients \\
\hline Quiet breathing & $2.53 \pm 0.55$ & $2.21 \pm 0.90$ & $2.86 \pm 0.43$ \\
\hline Voluntary sniffing & $3.93 \pm 0.90$ & $3.39 \pm 1.41$ & $5.12 \pm 1.08$ \\
Deep breathing & $6.75 \pm 0.95$ & $3.90 \pm 1.64^{*}$ & $7.38 \pm 1.59$ \\
\hline
\end{tabular}

Values are presented as mean \pm standard deviation.

${ }^{*} \mathrm{p}<0.05$.

Table 4. Left diaphragmatic excursion in control subjects and right- and left-hemiplegic patients (unit, $\mathrm{cm}$ )

\begin{tabular}{lccc}
\hline & Control subjects & Right-hemiplegic patients & Left-hemiplegic patients \\
\hline Quiet breathing & $2.39 \pm 0.59$ & $2.36 \pm 0.35$ & $1.59 \pm 0.37^{*}$ \\
Voluntary sniffing & $3.78 \pm 0.52$ & $3.57 \pm 0.64$ & $1.83 \pm 1.97^{* *}$ \\
Deep breathing & $6.47 \pm 0.96$ & $4.90 \pm 1.46$ & $3.23 \pm 1.08^{* *}$ \\
\hline
\end{tabular}

Values are presented as mean \pm standard deviation.

${ }^{*} \mathrm{p}<0.05,{ }^{* *} \mathrm{p}<0.01$.

\section{DISCUSSION}

Stroke patients are predisposed to hypoxia due to changes in the central regulation of respiration [17], sleep apnea [18], and weakness of the respiratory muscles [19]. In our study, oxygen saturation values were lower in stroke patients than in control subjects; however, this difference was not statistically significant. This may be due to the characteristics of the patients recruited and the time of oxygen-saturation measurement. We included only those stroke patients without any of the risk factors that contribute to hypoxia, such as smoking, atrial fibrillation, and ischemic heart disease. Additionally, $\mathrm{SaO}_{2}$ monitoring was performed in the afternoon or early evening before night. Stroke patients have a lower mean nocturnal oxygen saturation than baseline daytime oxygen saturation and exhibit a high prevalence of nocturnal hypoxia $[20,21]$. The $\mathrm{ETCO}_{2}$ of stroke patients was lower than that of control subjects, and this may be attributable to central hyperventilation or a respiratory compensation mechanism [20]. The $\mathrm{FEV}_{1}, \mathrm{FEV}_{1}$ (\% of predicted), FVC, and FVC (\% of predicted) were significantly lower in stroke patients compared to those in control subjects, and all stroke patients had restrictive pulmonary dysfunction, as observed in previous studies $[19,22]$. The deterioration of respiratory function in stroke patients may result in decreased aerobic exercise endurance and reduced cough effectiveness, contributing to frequent respiratory infections that can increase morbidity, mortal- ity, and hospitalizations. It is thus important to provide rehabilitation therapy to improve pulmonary function in stroke patients.

The majority of measurements obtained from control subjects for our ultrasonographic analysis of diaphragmatic excursion were higher in men than in women because gender is an important factor in diaphragmatic excursion [8]. Most of the diaphragmatic excursions of controls in our study were higher than those in the study of Boussuges et al. [8]. This may have resulted from differences in posture during the ultrasonographic study. Diaphragmatic motion is greater in the supine position than in the erect or sitting position because the postural control exercised by the crural portion of the diaphragm is eliminated in the supine position, allowing greater excursion [23]. Subjects in the study conducted by Boussuges et al. [8] were standing when they underwent ultrasonographic measurements. However, our subjects were in the supine position, with a $30^{\circ}$ inclination of the upper part of the body.

In our study, left-hemiplegic patients showed a significant decrease in diaphragm movement during quiet breathing, voluntary sniffing, and deep breathing compared to that showed by control subjects. We also observed a significant reduction in diaphragmatic excursion on the hemiplegic side during deep breathing by right-hemiplegic patients compared to that by controls. A significant reduction was observed only unilaterally on the hemiplegic side, primarily during volitional breathing 
(voluntary sniffing, deep breathing) rather than during autonomic breathing (quiet breathing). This observation is consistent with the study conducted by Cohen et al. [5] that reported that half of stroke patients had significantly reduced diaphragmatic excursion on the hemiplegic side during voluntary breathing. This reduction may result from the properties of the innervations. Many studies using cortical magnetic stimulation have demonstrated that each hemidiaphragm is represented in the unilateral contralateral cortex $[19,24,25]$. However, in our study, no significant reduction in hemiplegic-sided diaphragmatic excursion was observed in right-hemiplegic patients during voluntary sniffing although it was volitional breathing. This may reflect a difference in the surrounding structures of the right and left diaphragm. For example, the liver adjacent to the right hemidiaphragm may protect it from the pressure exerted by the visceral contents that can interfere with diaphragmatic excursion during inspiration. However, this does not occur on the left side. Thus, the left hemidiaphragm may experience more significant reductions than the right hemidiaphragm. There was also a significant reduction in diaphragmatic excursion among left-hemiplegic patients during quiet breathing, which is not volitional breathing. Despite taking great care to ensure that breathing was automatic, we could not be absolutely certain that all breaths during the examination were non-volitional, and it is possible that combined autonomic and voluntary breathing occurred. We also observed a difference in the gross pattern of the changes in the diaphragmatic excursion of hemiplegic patients compared to that in control subjects, although the difference was not statistically significant. Specifically, diaphragmatic excursion was reduced in righthemiplegic patients on both sides; however, in left-hemiplegic patients, it was reduced on the left hemiplegic side and increased on the right side, likely as a result of some underlying compensatory mechanism [5]. This may have been partially caused by the various forms of cerebral lesions in the affected hemisphere; these lesions may affect corticospinal projections to the phrenic nucleus differently in right- and left-hemiplegic patients. Additionally, we believe that there may be asymmetry in the cortical representation of the right and left hemidiaphragms. However, no extant published study has demonstrated cerebral dominance for diaphragm innervations that would involve differences in cortical representations between right and left hemidiaphragms [26]. Despite the limited ability to generalize these patterns due to the small number of subjects in this study, further research involving larger numbers of stroke patients followed over a longer period of time will likely yield meaningful results.

Cohen et al. [5] noted a significant positive correlation between diaphragmatic excursion and inspired volume in hemiplegic patients. In the present study, we also observed a significant positive correlation between left diaphragmatic excursion during deep breathing by ultrasonography and spirometric volumes $\left(\mathrm{FEV}_{1}:\right.$ rho $=0.79$, $\mathrm{p}=0.021$; FVC: $r h o=0.86, \mathrm{p}=0.007$ ). Thus, ultrasonography can facilitate the non-invasive quantification of diaphragmatic motion that is correlated with spirometric volumes. This technique also enables permanent recording of results for follow-up studies. Therefore, ultrasonography may be useful in the pulmonary evaluation of stroke patients. The reason why significant correlation between diaphragmatic excursion and spirometric volumes is obtained during deep breathing may be associated with the characteristics of the FVC and $\mathrm{FEV}_{1}$ maneuvers. These maneuvers assume a full inhalation through deep breathing, rather than quiet breathing, and voluntary sniffing prior to beginning the exhalation [16]. Moreover, a significant correlation was noted on only one side of the diaphragm, which is inconsistent with the findings of Cohen et al. [5] who reported correlations on both sides. Systematic differences in the method of measurement would contribute to this discrepancy. Correlation between the inspired volume and hemidiaphragmatic motion was better in the supine position [27]. However, in the present study, the measurements were not performed with the patients in the supine position, whereas Cohen et al. [5] did perform measurements in the supine position. Another possible explanation for the discrepancy is that spirometry and ultrasonography were not measured simultaneously in the present study, unlike in the study of Cohen et al. [5] who performed ultrasonography and airflow measurements simultaneously. We observed no significant correlation between K-MBI scores and diaphragmatic excursion or pulmonary function in the stroke patients, which may be due to the characteristics of K-MBI items themselves. K-MBI items primarily assess the basic life skills that require actions of the upper and lower skeletal muscles. They do not require a high level 
of aerobic exercise capacity or endurance. These findings indicate that using diaphragm ultrasonography to accurately predict K-MBI may be difficult. However, further research is needed to confirm this point.

One limitation of this study was that we performed the ultrasonography free-hand. Despite our attempt to maintain a firm position on the abdominal plane during ultrasonography, minor movements were probably caused by variations in the incident angle of the probe beam that would not have occurred with the use of a fixed device. In addition, since the number of subjects was small and the study involved stroke patients who were selected according to strict criteria, there may be limitations in applying the results of this study to all stroke patients. However, the significance of this study lies in the fact that it revealed the usefulness of evaluating diaphragmatic motion via $\mathrm{M}$-mode ultrasonography, which is a means of assessing pulmonary function in rehabilitation. Moreover, this study can be a cornerstone for further research to confirm the effects of stroke on diaphragmatic motion in terms of the correlation between diaphragmatic excursion and pulmonary function or functional level.

In conclusion, stroke patients had a significant decline in unilateral hemidiaphragmatic motion and pulmonary function compared to those in control subjects. Therefore, these should be assessed prior to rehabilitation to prevent pulmonary complications that would increase the associated morbidity and mortality. M-mode ultrasonography can be useful for this purpose since it is a non-invasive method for evaluating hemidiaphragmatic motion by providing quantitative information that is correlated with pulmonary function test.

\section{CONFLICT OF INTEREST}

No potential conflict of interest relevant to this article was reported.

\section{REFERENCES}

1. Aminoff MJ, Sears TA. Spinal integration of segmental, cortical and breathing inputs to thoracic respiratory motoneurones. J Physiol 1971;215:557-75.

2. Manning HL, Leiter JC. Respiratory control and respiratory sensation in a patient with a ganglioglioma within the dorsocaudal brain stem. Am J Respir Crit
Care Med 2000;161:2100-6.

3. Guz A. Brain, breathing and breathlessness. Respir Physiol 1997; 109:197-204.

4. Houston JG, Morris AD, Grosset DG, Lees KR, McMillan N, Bone I. Ultrasonic evaluation of movement of the diaphragm after acute cerebral infarction. J Neurol Neurosurg Psychiatry 1995;58:738-41.

5. Cohen E, Mier A, Heywood P, Murphy K, Boultbee J, Guz A. Diaphragmatic movement in hemiplegic patients measured by ultrasonography. Thorax 1994;49:890-5.

6. Houston JG, Fleet M, Cowan MD, McMillan NC. Comparison of ultrasound with fluoroscopy in the assessment of suspected hemidiaphragmatic movement abnormality. Clin Radiol 1995;50:95-8.

7. Ayoub J, Metge L, Dauzat M, Lemerre C, Pourcelot L, Prefaut C, et al. Diaphragm kinetics coupled with spirometry: M-mode ultrasonographic and fluoroscopic study: preliminary results. J Radiol 1997;78:563-8.

8. Boussuges A, Gole Y, Blanc P. Diaphragmatic motion studied by M-mode ultrasonography: methods, reproducibility, and normal values. Chest 2009;135:391400.

9. Testa A, Soldati G, Giannuzzi R, Berardi S, Portale G, Gentiloni Silveri N. Ultrasound M-mode assessment of diaphragmatic kinetics by anterior transverse scanning in healthy subjects. Ultrasound Med Biol 2011;37:44-52.

10. Cocchiarella L, Andersson G. Guides to the evaluation of permanent impairment. 5th ed. Chicago, IL: American Medical Association; 2001.

11. Roffe C, Sills S, Wilde K, Crome P. Effect of hemiparetic stroke on pulse oximetry readings on the affected side. Stroke 2001;32:1808-10.

12. Young DA, Simon G. Certain movements measured on inspiration-expiration chest radiographs correlated with pulmonary function studies. Clin Radiol 1972;23:37-41.

13. Houston JG, Morris AD, Howie CA, Reid JL, McMillan $\mathrm{N}$. Technical report: quantitative assessment of diaphragmatic movement: a reproducible method using ultrasound. Clin Radiol 1992;46:405-7.

14. Harris RS, Giovannetti M, Kim BK. Normal ventilatory movement of the right hemidiaphragm studied by ultrasonography and pneumotachography. Radiology 1983;146:141-4.

15. Gierada DS, Curtin JJ, Erickson SJ, Prost RW, Strandt 
JA, Goodman LR. Diaphragmatic motion: fast gradient-recalled-echo MR imaging in healthy subjects. Radiology 1995;194:879-84.

16. American Thoracic Society; European Respiratory Society. ATS/ERS statement on respiratory muscle testing. Am J Respir Crit Care Med 2002;166:518-624.

17. Nachtmann A, Siebler M, Rose G, Sitzer M, Steinmetz H. Cheyne-Stokes respiration in ischemic stroke. Neurology 1995;45:820-1.

18. Bassetti C, Aldrich MS. Sleep apnea in acute cerebrovascular diseases: final report on 128 patients. Sleep 1999;22:217-23.

19. Khedr EM, El Shinawy O, Khedr T, Aziz Ali YA, Awad EM. Assessment of corticodiaphragmatic pathway and pulmonary function in acute ischemic stroke patients. Eur J Neurol 2000;7:323-30.

20. Roffe C, Sills S, Halim M, Wilde K, Allen MB, Jones $\mathrm{PW}$, et al. Unexpected nocturnal hypoxia in patients with acute stroke. Stroke 2003;34:2641-5.

21. Ali K, Cheek E, Sills S, Crome P, Roffe C. Day-night differences in oxygen saturation and the frequency of desaturations in the first 24 hours in patients with acute stroke. J Stroke Cerebrovasc Dis 2007;16:239-44.
22. Fugl-Meyer AR, Linderholm H, Wilson AF. Restrictive ventilatory dysfunction in stroke: its relation to locomotor function. Scand J Rehabil Med Suppl 1983;9:11824.

23. Takazakura R, Takahashi M, Nitta N, Murata K. Diaphragmatic motion in the sitting and supine positions: healthy subject study using a vertically open magnetic resonance system. J Magn Reson Imaging 2004;19:605-9.

24. Similowski T, Catala M, Rancurel G, Derenne JP. Impairment of central motor conduction to the diaphragm in stroke. Am J Respir Crit Care Med 1996; 154(2 Pt 1):436-41.

25. Maskill D, Murphy K, Mier A, Owen M, Guz A. Motor cortical representation of the diaphragm in man. J Physiol 1991;443:105-21.

26. Howard RS, Rudd AG, Wolfe CD, Williams AJ. Pathophysiological and clinical aspects of breathing after stroke. Postgrad Med J 2001;77:700-2.

27. Houston JG, Angus RM, Cowan MD, McMillan NC, Thomson NC. Ultrasound assessment of normal hemidiaphragmatic movement: relation to inspiratory volume. Thorax 1994;49:500-3. 